Article

\title{
Immediate Impact of the COVID-19 Confinement on Physical Activity Levels in Spanish Adults
}

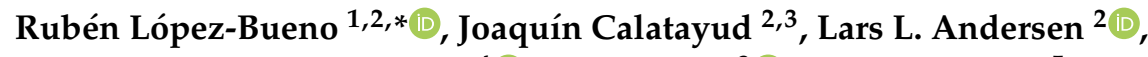 \\ Carlos Balsalobre-Fernández ${ }^{4} \mathbb{C}$, José Casaña ${ }^{3}{ }^{\circledR}$, José A. Casajús ${ }^{5}$, Lee Smith ${ }^{6}{ }^{\circledR}$ and \\ Guillermo F. López-Sánchez $7, *$ (i) \\ 1 Department of Physical Medicine and Nursing, University of Zaragoza, 50009 Zaragoza, Spain \\ 2 National Research Centre for the Working Environment, 2100 Copenhagen, Denmark; \\ joaquin.calatayud@uv.es (J.C.); lla@nfa.dk (L.L.A.) \\ 3 Exercise Intervention for Health Research Group (EXINH-RG), Department of Physiotherapy, University of \\ Valencia, 46010 Valencia, Spain; jose.casana@uv.es \\ 4 Applied Biomechanics and Sports Technology Research Group, Department of Physical Education, Sports, \\ and Human Motricity, Autonomous University of Madrid, 28049 Madrid, Spain; \\ carlos.balsalobre@icloud.com \\ 5 Faculty of Health Sciences, University of Zaragoza, 50009 Zaragoza, Spain; joseant@unizar.es \\ 6 Cambridge Centre for Sport and Exercise Science, Anglia Ruskin University, Cambridge CB1 1PT, UK; \\ Lee.Smith@anglia.ac.uk \\ 7 Faculty of Sport Sciences, University of Murcia, 30720 Murcia, Spain \\ * Correspondence: rlopezbu@unizar.es (R.L.-B.); gfls@um.es (G.F.L.-S.)
}

Received: 8 June 2020; Accepted: 13 July 2020; Published: 16 July 2020

check for updates

\begin{abstract}
Enacted measures to control the spread of COVID-19 disease such as compulsory confinement may influence health behaviors. The present study investigated changes in physical activity (PA) levels during the first days of confinement. Using an online survey, the Spanish population ( $\mathrm{n}=2042,54 \%$ women, age 35.9 (SD 13.6) years) replied to questions concerning sociodemographic characteristics as well as PA behavior before and during the first week of enacted isolation. Physical activity vital sign (PAVS) short form was used to estimate weekly minutes of PA before and during the isolation period. Statistical analysis used the following tests: Mc Nemar Chi-squared tests, independent and paired samples $t$-test, and effect size (Cohen's d). During the first week of confinement, participants reduced their weekly PA levels by $20 \%(\sim 45.2$ weekly minutes (95\% CI: $37.4-53.0)$ ). This led to a decrease from $60.6 \%$ to $48.9 \%$ (difference: $11.7 \%)(p<0.0001)$ in the number of participants meeting the recommended World Health Organization (WHO) PA levels. Subgroups including men, participants aged 43 or over, and those not holding a university degree had the greatest reductions in both weekly minutes of PA and adherence to guidelines. The PA levels of the Spanish population generally declined during the first days of COVID-19 confinement.
\end{abstract}

Keywords: physical exercise; lockdown; health-risk behaviors; isolation

\section{Introduction}

Coronavirus disease 2019 (COVID-19) was declared a global pandemic by the World Health Organization (WHO) on 11th March of 2020 [1]. At the time of writing the present document (29 March 2020), 634,813 cases had been diagnosed globally, resulting in 29,891 fatalities thus far [2], and Spain ranked as one of the most inflicted countries, with a total of 85,195 cases diagnosed and 7340 fatalities thus far [3]. On the 15th March of 2020, the Spanish Government approved a period of confinement in order to fight the spread of COVID-19 [4,5]. During the confinement period, the Spanish population had to stay at home and, in consequence, interrupt their usual activities; 
owing to these restrictions, physical activity (PA) levels can be dramatically affected since Spanish citizens are recommended to telework and do PA at home instead of training in either sports facilities or outdoors [4-6]. Time spent outdoors has been associated with higher levels of PA, higher physical fitness, and lower sedentary behavior, whereas outdoor sports have been linked to a wide-range of health benefits; thus, Spanish citizens without access to open spaces or green areas might experience a decline in their PA levels $[7,8]$.

Although exhaustive exercise, overtraining, or high-intensity exercise may lead to immunosuppression [9], emerging evidence suggests that regular PA enhances the immune function and increases resistance to infections compared with a sedentary lifestyle [10-16]. Even when performing PA below the recommended guidelines, the long-term risk of death from infectious disease lowered $40 \%$ [17]. The effects of PA on the immune function are also acute, as PA also produces an acute immune response [18]. Furthermore, one prospective study found PA associated with a decreased risk of community-acquired pneumonia among women [19], and pneumonia is one of the complications caused by COVID-19 in some infected people [20]. Moreover, this is not only a question of physical health but also a mental health issue, since a social isolation context and perception of loneliness predicted both anxiety and depression symptoms in older people, and could lead to both poor mental health as well as a higher likelihood of suicidal ideation [21-23], which might be attenuated through PA [24-26].

Furthermore, moderate PA improves mood [27] and helps to prevent and reduce anxiety and depression [28]. Also, previous research has found that PA produces not only long-term benefits in mental health, but also immediate psychological benefits for mood, anxiety, and stress due to the acute effects of PA [29-31]. Therefore, given the benefits of PA to physical and mental health, it seems very important that people meet the global recommendations for PA set out by WHO during the confinement period [32], although during this confinement period the PA should be carried out at home to ensure government social distancing requirements are being maintained. Throughout a week, WHO recommends that adults perform at least $150 \mathrm{~min}$ of moderate-intensity aerobic PA, or 75 min of vigorous-intensity PA, or an equivalent combination of moderate- and vigorous-intensity aerobic PA; WHO also recommends that muscle-strengthening activities should be performed involving major muscle groups on two or more days a week [32].

Some recent studies with a large representative sample of Spanish adults, carried out before the confinement period, have indicated that $70 \%$ of Spanish adults meet recommended PA guidance set out by WHO, although these results were based on self-report and may be overestimated [33]. Moreover, since performing PA outdoors has been restricted during the COVID-19 confinement, data from Spain might be lower than in other European countries, likely having a greater impact on the population's health. Given the importance of PA to health, this study aimed to quantify the change in PA of the Spanish adult population during the COVID-19 confinement compared with before confinement. Quantification of this change is important to provide practical recommendations, e.g., on physical activities to perform at home.

We hypothesized that PA will decrease in Spanish adults during the first days of confinement. The results of this study can be very useful for countries where PA outdoors is still forbidden and for future coronavirus resurgence that can make necessary new confinements, helping to design and implement measures that guarantee that the population can do adequate levels of PA during confinements.

\section{Materials and Methods}

\subsection{The Survey}

A cross-sectional online survey design concerning health habits was conducted during the COVID-19 outbreak in Spain. A web-form link available from the 22nd to the 29th of March 2020 (i.e., from the seventh official day of Government-enacted national confinement) was launched on 
social media encouraging users to answer the survey. Convenience sampling was used to select the participants of the study; according to server analytics, 2850 media users covering all the Spanish regions were asked to participate. Participants were previously informed about the purposes of the study, gave informed consent to participate, and indicated whether they were in a confinement situation. Provided data were anonymous and treated according to Spanish law regarding general data protection. Once the survey was completed, the participants were provided with advice on how to be active at home and its benefits. The present study retrieved data from the survey in relation to the following variables: PA (i.e., before and during the confinement), age, gender, civil status, occupation, and education.

The study followed the principles of the World Medical Declaration of Helsinki, and got the approval of the Ethics Committee of Research in Humans of the University of Valencia (register code 1278789). The reporting of this study follows the guidelines of the Strengthening the Reporting of Observational Studies in Epidemiology statement (STROBE) [34].

\subsection{Physical Activity}

Assessment of PA was conducted through physical activity vital sign (PAVS) short form, in which participants answered two questions regarding the number of days they were engaged in PA during a usual week, and the average minutes they usually performed PA in those days; participants could select between 0 to 7 days of PA a week and 10, 20,30,40,50, 60, 90, and 150 or more daily minutes [35]. The PAVS was asked twice to the participants; first referred to the PA they usually performed before the confinement, and second referred to the isolation period. In order to apply PAVS to that particular context of confined population, the word "usual" was replaced for "isolation" when referring to the week they performed PA. Following PAVS original procedure, weekly minutes of PA were calculated by multiplying days with minutes. Participants were later classified in accordance with the WHO recommendations for moderate-intensity aerobic PA.

Moreover, data on how PA was performed by the participants while the COVID-19 isolation through the following question: "What types of physical activity do you usually perform during the isolation period?" and answers comprised "household (e.g., cooking, cleaning, or similar)," "endurance exercise (e.g., stationary bicycle, treadmill, elliptical, aerobics, Zumba, or similar)," "resistance exercise (e.g., calisthenics, raising barbells, resistance bands, or similar)," "flexibility (e.g., individual stretching, stretching with a partner, or similar)," "electrostimulation, vibratory platform, or similar," "active videogames (e.g., Playstation, X-box, or similar)," "applications for mobile devices," and "not performing physical activity."

\subsection{Demographic Characteristics}

Given previous research [34,35], the study also estimated age, gender, civil status, occupation, and education as factors. All variables were self-reported by the participants and categorized as follows: Civil status ("married" or "not married"), occupation ("employed" or "not employed"), and education ("having a university degree" or "not having a university degree").

\subsection{Statistical Analyses}

Statistical analyses were conducted through the Statistical Package for Social Sciences (SPSS) version 23.0 (SPSS Inc., Chicago, IL, USA). The Kołmogorov-Smirnov test was applied to check normality. Paired $t$-tests were performed for each subgroup to examine PA differences within each subgroup for each characteristic. Independent $t$-tests were performed on the subgroup differences to determine whether the subgroup differences varied within each characteristic. Differences in relation to prevalence of WHO guidelines were evaluated by Mc Nemar Chi-squared tests, providing the frequencies and percentages of each group, the percentage difference, $\chi 2$ value, degres of freedom, and $p$-values. To check differences regarding demographic characteristics, the analyses were stratified for each one of the factors. A cut-off point for age (i.e., 43 years) was estimated through a data-driven 
approach using receiver operating characteristic (ROC) curve analysis. There were no missing data. Levels of significance were set at $p<0.05$. In addition, the effect size was calculated using Cohen's $d$, classified as small (0.20), medium (0.50), and large (0.80).

\section{Results}

A total of 2042 participants on average aged 35.9 (SD 13.6) completed the survey. Table 1 presents the descriptive statistics for the sample, in which 1104 participants (54.1\%) were women, 1001 (49.0\%) were married, 1293 (63.3\%) held a university degree, and 1287 (63.0\%) were employed.

Table 1. Differences between physical activity (PA) performed before and during COVID-19 confinement.

\begin{tabular}{|c|c|c|c|c|c|c|c|c|c|c|}
\hline & n & $\%$ & $\begin{array}{c}\text { Weekly PA } \\
\text { Minutes before } \\
\text { Isolation } \\
\text { Mean } \pm \text { SD }\end{array}$ & $\begin{array}{c}\text { Weekly PA } \\
\text { Minutes during } \\
\text { Isolation } \\
\text { Mean } \pm \text { SD }\end{array}$ & $\begin{array}{c}\text { Difference of } \\
\text { Weekly PA } \\
\text { Minutes } \\
\text { (before and } \\
\text { during } \\
\text { Isolation) } \pm \text { SD }\end{array}$ & $t$ & df & $p$ Value $^{\mathrm{a}}$ & $d^{\mathrm{b}}$ & $p$ Value $^{\mathrm{c}}$ \\
\hline Overall & 2042 & & $221.9 \pm 193.6$ & $176.7 \pm 178.9$ & $45.2 \pm 179.9$ & 11.3486 & 2041 & $<0.0001$ & 0.2424 & \\
\hline Gender & & & & & & & & & & $<0.0001$ \\
\hline Men & 938 & 45.9 & $268.8 \pm 207.1$ & $196.0 \pm 185.0$ & $72.9 \pm 177.0$ & 12.5392 & 937 & $<0.0001$ & 0.3703 & \\
\hline $\begin{array}{l}\text { Women } \\
\text { Age }\end{array}$ & 1104 & 54.1 & $182.0 \pm 171.7$ & $160.4 \pm 171.2$ & $21.7 \pm 178.3$ & 4.0381 & 1103 & $<0.0001$ & 0.1264 & 0.1074 \\
\hline$<43$ years & 1441 & 70.6 & $238.4 \pm 201.4$ & $196.4 \pm 181.9$ & $42.0 \pm 183.0$ & 8.7093 & 1440 & $<0.0001$ & 0.2188 & \\
\hline$\geq 43$ years & 601 & 29.4 & $182.4 \pm 167.3$ & $129.6 \pm 162.4$ & $52.8 \pm 172.1$ & 7.5255 & 600 & $<0.0001$ & 0.3205 & \\
\hline Civil status & & & & & & & & & & 0.1951 \\
\hline Married & 1001 & 49.0 & $210.1 \pm 187.6$ & $161.4 \pm 170.6$ & $48.7 \pm 173.7$ & 8.8637 & 1000 & $<0.0001$ & 0.2715 & \\
\hline $\begin{array}{l}\text { Not married } \\
\text { Education }\end{array}$ & 1041 & 51.0 & $233.2 \pm 198.8$ & $191.4 \pm 185.5$ & $41.8 \pm 185.7$ & 7.2681 & 1040 & $<0.0001$ & 0.2176 & 0.0011 \\
\hline $\begin{array}{l}\text { University } \\
\text { degree } \\
\text { No }\end{array}$ & 1293 & 63.3 & $217.2 \pm 180.7$ & $181.3 \pm 174.4$ & $36.0 \pm 174.2$ & 7.4155 & 1292 & $<0.0001$ & 0.2023 & \\
\hline $\begin{array}{l}\text { University } \\
\text { degree }\end{array}$ & 749 & 36.7 & $221.9 \pm 180.7$ & $168.8 \pm 186.4$ & $61.2 \pm 188.4$ & 8.8845 & 748 & $<0.0001$ & 0.3048 & \\
\hline Occupation & & & & & & & & & & 0.0249 \\
\hline Employed & 1287 & 63.0 & $205.0 \pm 180.0$ & $165.6 \pm 168.7$ & $39.2 \pm 175.2$ & 8.0281 & 1286 & $<0.0001$ & 0.2247 & \\
\hline $\begin{array}{c}\text { Not } \\
\text { employed }\end{array}$ & 755 & 37.0 & $251.0 \pm 212.0$ & $195.6 \pm 193.7$ & $55.4 \pm 187.4$ & 8.1205 & 754 & $<0.0001$ & 0.2728 & \\
\hline
\end{tabular}

${ }^{a}$ T-paired test (PA before and during isolation). ${ }^{\mathrm{b}}$ Cohen's d: Small 0.20; Medium 0.50; Large 0.80. ${ }^{\mathrm{c}}$ T-test for independent subgroups within categories.

Regarding WHO guidelines concerning PA, participants from all categories presented lower values during the isolation in Table 2.

Table 2. Adherence to World Health Organization (WHO) PA guidelines before and during COVID-19 confinement.

\begin{tabular}{|c|c|c|c|c|c|c|c|c|c|}
\hline & \multicolumn{2}{|c|}{ WHO before } & \multicolumn{2}{|c|}{ WHO isolated } & \multirow[b]{2}{*}{ Difference } & \multirow[b]{2}{*}{$x^{2}$} & \multirow[b]{2}{*}{ df } & \multirow[b]{2}{*}{$p$ Value $^{\mathbf{a}}$} & \multirow[b]{2}{*}{$d^{\mathrm{b}}$} \\
\hline & $\mathbf{n}$ & $\%$ & $\mathrm{n}$ & $\%$ & & & & & \\
\hline Overall & 1238 & 60.6 & 999 & 48.9 & 11.7 & 16.67 & 1 & $<0.0001$ & 0.2367 \\
\hline \multicolumn{10}{|l|}{ Gender } \\
\hline Men & 662 & 70.6 & 502 & 53.5 & 17.1 & 94.12 & 1 & $<0.0001$ & 0.3569 \\
\hline $\begin{array}{l}\text { Women } \\
\text { Age }\end{array}$ & 576 & 52.2 & 497 & 45.0 & 7.2 & 17.19 & 1 & $<0.0001$ & 0.1435 \\
\hline$<43$ years & 928 & 64.4 & 792 & 55.0 & 9.4 & 43.42 & 1 & $<0.0001$ & 0.1932 \\
\hline$\geq 43$ years & 310 & 51.6 & 207 & 34.4 & 17.2 & 50.76 & 1 & $<0.0001$ & 0.3512 \\
\hline \multicolumn{10}{|l|}{ Civil status } \\
\hline Married & 593 & 59.2 & 461 & 46.1 & 13.1 & 52.80 & 1 & $<0.0001$ & 0.2663 \\
\hline $\begin{array}{l}\text { Not married } \\
\text { Education }\end{array}$ & 645 & 61.0 & 538 & 51.7 & 9.3 & 37.54 & 1 & $<0.0001$ & 0.2085 \\
\hline University degree & 798 & 61.7 & 667 & 51.6 & 10.1 & 42.37 & 1 & $<0.0001$ & 0.2054 \\
\hline $\begin{array}{c}\text { No University degree } \\
\text { Occupation }\end{array}$ & 440 & 58.7 & 332 & 44.3 & 14.4 & 50.71 & 1 & $<0.0001$ & 0.2914 \\
\hline Employed & 750 & 58.3 & 606 & 47.1 & 11.2 & 52.36 & 1 & $<0.0001$ & 0.2254 \\
\hline Not employed & 488 & 64.6 & 393 & 52.1 & 12.5 & 37.76 & 1 & $<0.0001$ & 0.2572 \\
\hline
\end{tabular}

a Mc Nemar's chi square test (WHO before and during isolation). ${ }^{\mathrm{b}}$ Cohen's d: Small 0.20; Medium 0.50; Large 0.80.

The overall percentage of reduction was $11.7 \%(p<0.0001)$ with values remaining significant for all the subgroups except for women. The subgroup of men and participants aged 43 or over showed higher reductions of WHO guidelines achievement with respectively $17.1 \%(p<0.0001)$ and $17.2 \%(p<0.0001)$. Concerning differences in the number of weekly PA minutes reduced during the 
COVID-19 isolation period, the subgroups of women $(p<0.0001)$, participants holding a university degree $(p<0.005)$, and employed $(p<0.05)$ showed significantly lower reductions of PA weekly minutes as regards their counterparts.

The subgroup aged 43 and over was the only one not reaching WHO guidelines regarding PA before and in the course of the confinement period. Minutes of PA declined during the isolation period for all subgroups; Table 1 also showed a significant difference of $45.2 \mathrm{~min}(p<0.0001)$ between the PA performed before and during the isolation for the overall sample. When examining the decline for each demographic characteristic, men, adults with no university education, and adults not employed reported significantly larger declines in minutes of PA.

As regards the way PA was performed during the COVID-19 isolation period, Figure 1 lists a range of activities that the participants performed. Household ranked first in this list (62.2\%), in which social networks and applications devices respectively accounted for $27.4 \%$ and $19.4 \%$ of the participants.

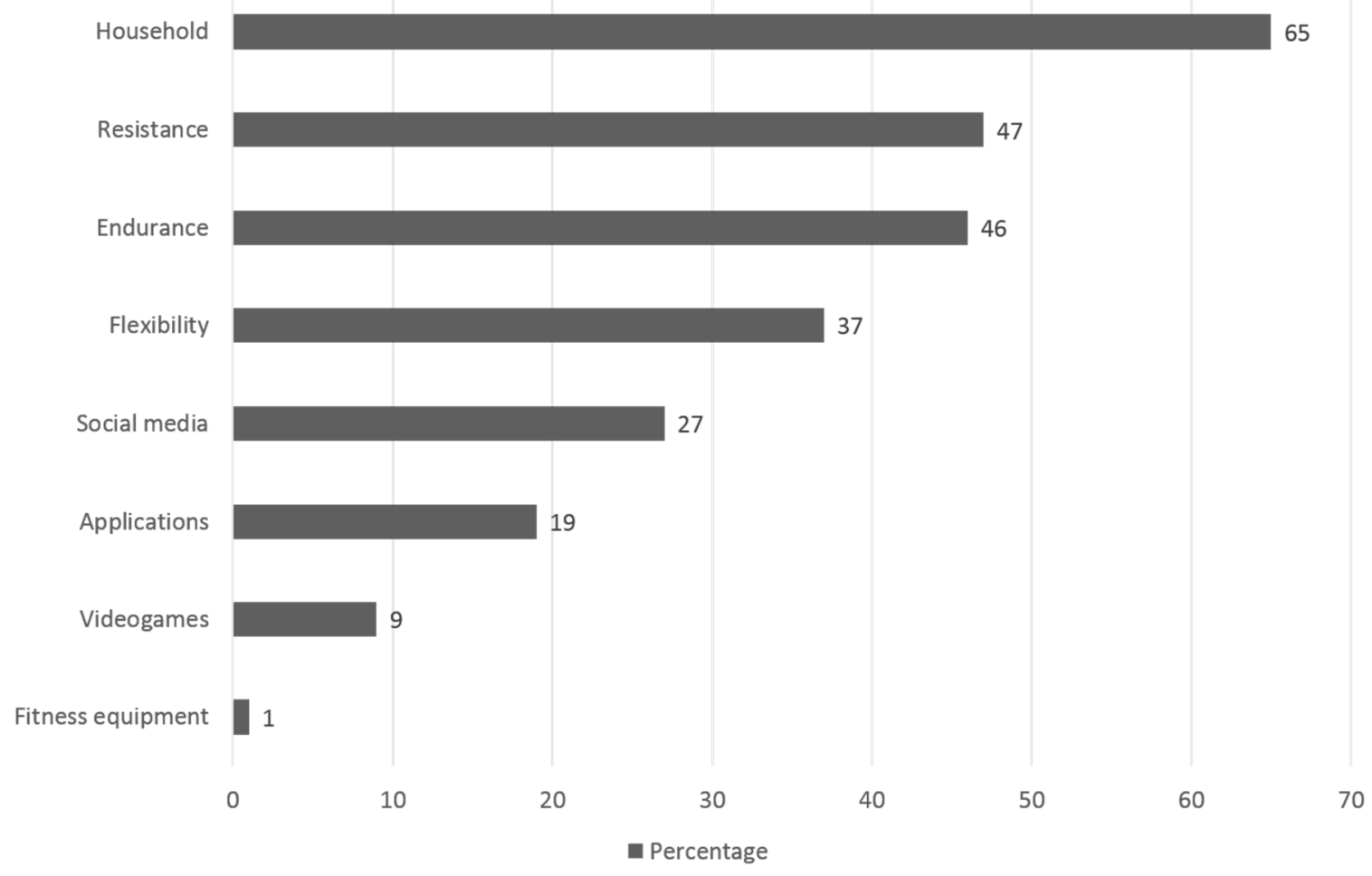

Figure 1. Ways of performing PA during COVID-19 isolation in Spain.

\section{Discussion}

Findings from the present study in a large sample of the Spanish adult population showed that PA weekly minutes significantly decreased by $20 \%$ with the COVID-19 confinement (Figure 2).

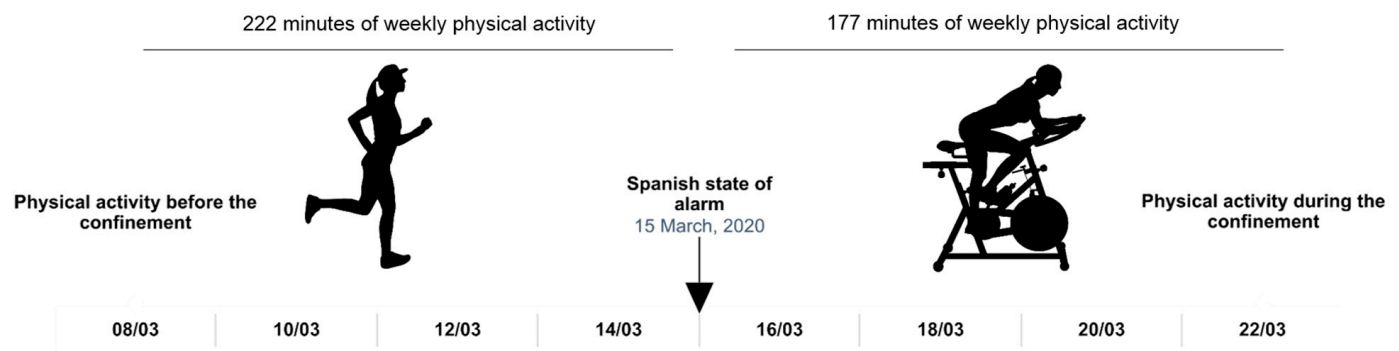

Figure 2. Estimated levels of weekly PA before and after the Spanish state of alarm. 
This reduction was particularly pronounced in men, older participants, and those with lower education levels. The results of the present study support the general notion that an isolation context associates with less PA, as observed in prior research with older adults [36]. Further, this study strengthens the findings found in recent research, in which adult populations showed lower PA levels during the COVID-19 confinement in all types of PA intensity levels, as well as in both physically active and inactive participants $[37,38]$. Nevertheless, our study provides novel data from an unknown setting, in which participants have not voluntarily decided to isolate themselves, and citizens of all ages had been officially ordered to stay at home for at least a month. Importantly, our study showed that only a week of isolation might have a great impact on PA reduction.

A report from the European Union (EU) found Spanish PA levels to be on average regarding other European countries, with 56\% never or seldom doing PA [39]. However, a study by Fernández-Navarro et al. [40] suggests a worse situation, in which around $73 \%$ of the Spanish population does not meet the WHO guidelines concerning PA, with a subsequent higher risk of chronic diseases; as observed in that research, our study also showed men to be more physically active than women, as well as the important role of education. On the other hand, our study points at a higher percentage of Spanish residents achieving PA recommended levels, particularly before the COVID-19 isolation, which could be due to substantial differences regarding age (i.e., our study sample of adults is younger compared to other studies). In fact, our study found lower levels of PA in older participants, which might be partly explained by the ageing process itself [41]. Another highlight was that university degree holders performed higher PA, and presented a lower decline of PA levels as regards their counterparts; one plausible explanation for this finding might be a higher awareness of having a healthy lifestyle, particularly in such an exceptional setting, since educational differences have been underscored to be a reliable predictor of leisure-time PA [42]. In accordance with previous research [43], unemployed participants of this study showed lower PA levels than those employed, although the fact that specific job roles (e.g., health workers or security forces and corps) are exempt from complying with the COVID-19 isolation governmental normative might partially explain these differences (i.e., working duties of specific job roles such as health workers and security corps might contribute to increase their PA levels).

Our study observed significant reductions in performed weekly PA as well as in adherence to WHO guidelines in all subgroups; however, such reductions mainly showed a small to medium effect size. Thus, according to this data, PA reductions are wide-spread within the sample without particularly focusing too much on any specific subgroup. Nevertheless, it is important to notice that the effect seemed to be more pronounced in groups with lower education as well as in the elderly, i.e., groups that are already at increased risk of lifestyle diseases. Thus, confinement may amplify existing inequalities in health across groups in society.

As expected, household chores were observed to be a prevalent PA content among the participants of this study. Due to the amount of time the participants are supposed to spend at home, the household accounts for an important part of the performed weekly PA. It is noticeable that social media and application devices are moderately used for PA purposes during this period, although our percentages are similar to others found in previous research [44]. Performing home-based PA through wearables and smartphone applications might be a way forward to promote sufficient PA during this confinement period, although the effects of their implementation to increase PA levels have been generally estimated between small to moderate, and it is still a challenge to reach the most physically inactive people with these type of tools [45].

Overall as well as subgroup reductions of weekly PA might be explained for the lack of social support and the feelings of loneliness, which have been associated with lower levels of PA and poor health conditions in both younger and older adults $[36,46,47]$. In fact, a prolonged time of social isolation has been observed to associate with cardiovascular diseases, poor mental health, and to increase all-cause mortality [22,48]. Social isolation and feelings of loneliness are current issues that, in this particular situation of confinement due to COVID-19, might be exacerbated by the fact that 
physical human interaction has been constrained for a significant period. In addition, natural light and natural environment exposure deprivation might lead to a worse mood and poor mental health, which consequently, might predispose for less PA [49]. Thus, anxiety may increase as the COVID-19 related mortality increases if the quarantine time continues [50]. Besides, prior research has observed lower socioeconomic status (i.e., lower educational level and unemployed) to increase the odds for joint health-risk behaviors involving physical activity, screen exposure, sleep time, fruits and vegetable consumption, alcohol consumption, and smoking habit [51] among Spanish adults confined due to COVID-19; hence future research focused on deprived populations, such as those from poorer backgrounds or those financially affected by the COVID-19 pandemic, would be of special interest.

Strengths of the current study include using a large and widespread sample of Spanish adults (i.e., participants from all the Spanish regions) and the use of a validated tool to assess PA. Moreover, the fact that significant reductions of PA levels and adherence to WHO guidelines have significantly decreased in all the study subgroups within a short-term, provides consistency to our findings. However, several limitations should be highlighted for this study. First, due to the fact that PA and other variables are self-reported, it might lead to information bias. Second, since young adults are overrepresented in the study sample, estimated PA levels might be higher than in the general Spanish population of adults; owing to the type of sampling, there is a possibility of selection bias. Third, due to the study design, the present work does not allow drawing causal inferences. Fourth, adjusted analyses for health status might lead to different results. Also, important aspects regarding PA (i.e., intensity levels) or critical health-related habits such as diet have not been reflected in this study. Last, because the collected data mainly referred to the first week of the COVID-19 outbreak in Spain, it might not properly reflect the big picture of the influence of social isolation and confinement over PA (i.e., more days of isolation might associate with even lower levels of PA). Thus, future research should investigate how PA levels are varying during this complete period.

\section{Conclusions}

The PA levels of the Spanish population generally declined during the first days of COVID-19 confinement. The promotion of home-based physical activities is particularly recommendable in this specific context to reach the recommended PA levels set out by WHO.

Author Contributions: Conceptualization, R.L.-B., J.C. (Joaquín Calatayud), L.S., and G.F.L.-S.; data curation, R.L.-B.; formal analysis, R.L.-B.; investigation, R.L.-B., J.C. (Joaquín Calatayud), and G.F.L.-S.; methodology, J.A.C. and L.S.; project administration, L.S. and G.F.L.-S.; software, R.L.-B.; supervision, G.F.L.-S.; validation, L.L.A., C.B.-F., and J.C. (José Casaña); visualization, R.L.-B.; writing—original draft, R.L.-B., L.S., and G.F.L.-S.; writing-review and editing, J.C. (Joaquín Calatayud), L.L.A., C.B.-F., J.C. (José Casaña), and J.A.C.. All authors have read and agreed to the published version of the manuscript.

Funding: This research received no external funding.

Acknowledgments: The authors express their gratitude to the respondents for their time and effort.

Conflicts of Interest: The authors declare no conflict of interest.

\section{References}

1. World Health Organization. Coronavirus Disease 2019 (COVID-19): Situation Report, 51. 2020. Available online: https://www.who.int/docs/default-source/coronaviruse/situation-reports/20200311-sitrep51-covid-19.pdf?sfvrsn=1ba62e57_10 (accessed on 22 March 2020).

2. World Health Organization. Coronavirus Disease 2019 (COVID-19): Situation Report, 69. 2020. Available online: https:/www.who.int/docs/default-source/coronaviruse/situation-reports/20200329-sitrep69-covid-19.pdf?sfvrsn=8d6620fa_8 (accessed on 29 March 2020).

3. Ministerio de Sanidad, Consumo y Bienestar Social. Enfermedad por Nuevo Coronavirus, COVID-19: Situación Actual. Actualización no 60; 2020. Available online: https://www.mscbs.gob.es/profesionales/ saludPublica/ccayes/alertasActual/nCov-China/situacionActual.htm (accessed on 30 March 2020).

4. Gobierno de España. 2020. Available online: https://www.lamoncloa.gob.es/ (accessed on 22 March 2020). 
5. Real Decreto 463/2020, de 14 de Marzo, por el que se Declara el Estado de Alarma para la Gestión de la Situación de Crisis Sanitaria Ocasionada por el COVID-19. 2020. Available online: https://www.boe.es/ buscar/doc.php?id=BOE-A-2020-3692 (accessed on 22 March 2020).

6. Consejo Superior de Deportes. 2020. Available online: https://www.csd.gob.es/es/la-campanayomemuevoencasa-del-csd-y-el-consejo-colef-recuerda-la-importancia-de-mantener-un-estilo-de-vidaactivo-durante (accessed on 24 March 2020).

7. Schaefer, L.; Plotnikoff, R.C.; Majumdar, S.R.; Mollard, R.; Woo, M.; Sadman, R.; Rinaldi, R.L.; Boulé, N.; Torrance, B.; Ball, G.D.C.; et al. Outdoor time is associated with physical activity, sedentary time, and cardiorespiratory fitness in youth. J. Pediatr. 2014, 165, 516-521. [CrossRef]

8. Eigenschenk, B.; Thomann, A.; McClure, M.; Davies, L.; Gregory, M.; Dettweiler, U.; Inglés, E. Benefits of outdoor sports for society. A systematic literature review and reflections on evidence. Int. J. Environ. Res. Public Health 2019, 16, 937. [CrossRef]

9. Wetmore, C.M.; Ulrich, C.M. Mechanisms associating physical activity with cancer incidence: Exercise and immune function. In Cancer Prevention And Management through Exercise and Weight Control; McTiernan, A., Ed.; CRC Press: Los Angeles, CA, USA, 2006; pp. 157-176.

10. Gleeson, M. Immune function in sport and exercise. J. Appl. Physiol. 2007, 103, 693-699. [CrossRef]

11. Mazzeo, R.S. Altitude, exercise and immune function. Exerc. Immunol. Rev. 2005, 11, 6-16. [PubMed]

12. Woods, J.A.; Lowder, T.W.; Keylock, K.T. Can exercise training improve immune function in the aged? Ann. N. Y. Acad. Sci. 2002, 959, 117-127. [CrossRef]

13. Woods, J.A.; Davis, J.M.; Smith, J.A.; Nieman, D.C. Exercise and cellular innate immune function. Med. Sci. Sports Exerc. 1999, 31, 5-66. [CrossRef] [PubMed]

14. Shephard, R.J.; Shek, P.N. Exercise, immunity, and susceptibility to infection: A J-shaped relationship? Phys. Sportsmed. 1999, 27, 47-71. [CrossRef] [PubMed]

15. Peters, E.M. Exercise, immunology and upper respiratory tract infections. Int. J. Sports Med. 1997, 18, S69-S77. [CrossRef] [PubMed]

16. Nieman, D.C.; Wentz, L.M. The compelling link between physical activity and the body's defense system. J. Sport Heal. Sci. 2019, 8, 201-217. [CrossRef]

17. Hamer, M.; Donovan, G.O.; Stamatakis, E. Lifestyle risk factors, obesity and infectious disease mortality in the general population: Linkage study of 97,844 adults from England and Scotland. Prev. Med. Baltim. 2019, 123, 65-70. [CrossRef]

18. Vider, J.; Lehtmaa, J.; Kullisaar, T.; Vihalemm, T.; Zilmer, K.; Kairane, A.; Landõr, A.; Karu, T.; Zilmer, M. Acute immune response in respect to exercise-induced oxidative stress. Pathophysiology 2001, 7, 263-270. [CrossRef]

19. Baik, I.; Curhan, G.C.; Rimm, E.B.; Bendich, A.; Willet, W.C.; Fawzi, W.W. A prospective study of age and lifestyle factors in relation to community-acquired pneumonia in US men and women. Arch. Intern. Med. 2000, 160, 3082-3088. [CrossRef] [PubMed]

20. Mayo Clinic. Coronavirus Disease 2019 (COVID-19). Available online: https://www.mayoclinic.org/diseasesconditions/coronavirus/symptoms-causes/syc-20479963 (accessed on 22 March 2020).

21. Calati, R.; Ferrari, C.; Brittner, M.; Oasi, O.; Olié, E.; Carvalho, A.F.; Courtet, P. Suicidal thoughts and behaviors and social isolation: A narrative review of the literature. J. Affect. Disord. 2019, 245, 653-667. [CrossRef] [PubMed]

22. Leigh-Hunt, N.; Bagguley, D.; Bash, K.; Turner, V.; Turnbull, S.; Valtorta, N.; Caan, W. An overview of systematic reviews on the public health consequences of social isolation and loneliness. Public Health 2017, 152, 157-171. [CrossRef] [PubMed]

23. Santini, Z.I.; Jose, P.E.; York Cornwell, E.; Koyanagi, A.; Nielsen, L.; Hinrichsen, C.; Meilstrup, C.; Madsen, K.R.; Koushede, V. Social disconnectedness, perceived isolation, and symptoms of depression and anxiety among older Americans (NSHAP): A longitudinal mediation analysis. Lancet Public Heal. 2020, 5, e62-e70. [CrossRef]

24. Chekroud, S.R.; Gueorguieva, R.; Zheutlin, A.B.; Paulus, M.; Krumholz, H.M.; Krystal, J.H.; Chekroud, A.M. Association between physical exercise and mental health in 1.2 million individuals in the USA between 2011 and 2015: A cross-sectional study. The Lancet Psychiatry 2018, 5, 739-746. [CrossRef]

25. Kandola, A.; Ashdown-Franks, G.; Hendrikse, J.; Sabiston, C.M.; Stubbs, B. Physical activity and depression: Towards understanding the antidepressant mechanisms of physical activity. Neurosci. Biobehav. Rev. 2019, 107, 525-539. [CrossRef] 
26. Cao, C.; Liu, Q.; Yang, L.; Zheng, X.; Lan, P.; Koyanagi, A.; Vancampfort, D.; Soysal, P.; Veronese, N.; Stubbs, B.; et al. Handgrip strength is associated with suicidal thoughts in men: Cross-sectional analyses from NHANES. Scand. J. Med. Sci. Sports 2019, 30,1-8. [CrossRef]

27. Peluso, M.A.M.; Guerra de Andrade, L.H.S. Physical activity and mental health: The association between exercise and mood. Clinics 2005, 60,61-70. [CrossRef]

28. Martinsen, E.W. Physical activity in the prevention and treatment of anxiety and depression. Nord. J. Psychiatry 2008, 62, 25-29. [CrossRef]

29. Szabo, A. Acute psychological benefits of exercise performed at self-selected workloads: Implications for theory and practice. J. Sport Sci Med. 2003, 2, 77-87.

30. Fleming, K.M.; Campbell, M.; Herring, M.P. Acute effects of Pilates on mood states among young adult males. Complement. Ther Med. 2020, 49, 102313. [CrossRef] [PubMed]

31. Morgan, W.P.; Horstman, D.H. Anxiety reduction following acute physical activity. Psychiatr. Ann. 1979, 9, 36-45. [CrossRef]

32. World Health Organization. Global Recommendations on Physical Activity for Health. 2014. Available online: https://www.who.int/dietphysicalactivity/factsheet_recommendations/en/ (accessed on 22 March 2020).

33. López-Sánchez, G.F.; Pardhan, S.; Trott, M.; Sánchez-Castillo, S.; Jackson, S.E.; Tully, M.; Gorely, T.; López-Bueno, R.; Veronese, N.; Skalska, M.; et al. The Association Between Physical Activity and Cataracts Among 17,777 People Aged 15-69 Years Residing in Spain. Ophthalmic Epidemiol. 2020, 27, 272-277. [CrossRef]

34. Vandenbroucke, J.P.; Von Elm, E.; Altman, D.G.; Gøtzsche, P.C.; Mulrow, C.D.; Pocock, S.J.; Poole, C.; Schlesselman, J.J.; Egger, M. Strengthening the Reporting of Observational Studies in Epidemiology (STROBE): Explanation and elaboration. PLoS Med. 2007, 4, 1628-1654. [CrossRef]

35. Greenwood, J.L.J.; Joy, E.A.; Stanford, J.B. The Physical Activity Vital Sign: A Primary Care Tool to Guide Counseling for Obesity. J. Phys. Act. Heal. 2010, 7, 571-576. [CrossRef]

36. Schrempft, S.; Jackowska, M.; Hamer, M.; Steptoe, A. Associations between social isolation, loneliness, and objective physical activity in older men and women. BMC Public Health 2019, 19, 1-10. [CrossRef]

37. Ammar, A.; Brach, M.; Trabelsi, K.; Chtourou, H.; Boukhris, O.; Masmoudi, L.; Bouaziz, B.; Bentlage, E.; How, D.; Ahmed, M.; et al. On Behalf of the ECLB-COVID19 Consortium. Effects of COVID-19 Home Confinement on Eating Behaviour and Physical Activity: Results of the ECLB-COVID19 International Online Survey. Nutrients 2020, 12, 1583. [CrossRef]

38. Lesser, I.A.; Nienhuis, C.P. The Impact of COVID-19 on Physical Activity Behavior and Well-Being of Canadians. Int. J. Environ. Res. Public Health 2020, 17, 3899. [CrossRef]

39. European Commission. Special Eurobarometer 472 Report Sport and Physical Activity Fieldwork. 2018. Available online: http://ec.europa.eu/commfrontoffice/publicopinion/index.cfm/survey (accessed on 23 March 2020).

40. Fernandez-Navarro, P.; Aragones, M.T.; Ley, V. Leisure-time physical activity and prevalence of non-communicable pathologies and prescription medication in Spain. PLoS ONE 2018, 13, 1-13. [CrossRef]

41. Milanović, Z.; Pantelić, S.; Trajković, N.; Sporiš, G.; Kostić, R.; James, N. Age-related decrease in physical activity and functional fitness among elderly men and women. Clin. Interv. Aging 2013, 8, 549-556. [CrossRef] [PubMed]

42. Mäkinen, T.E.; Sippola, R.; Borodulin, K.; Rahkonen, O.; Kunst, A.; Klumbiene, J.; Regidor, E.; Ekholm, O.; MacKenbach, J.; Prättälä, R. Explaining educational differences in leisure-time physical activity in Europe: The contribution of work-related factors. Scand. J. Med. Sci. Sport 2012, 22, 439-447. [CrossRef]

43. Mohammad Ali, S.; Lindström, M. Psychosocial work conditions, unemployment, and leisure-time physical activity: A population-based study. Scand. J. Public Health 2006, 34, 209-216. [CrossRef] [PubMed]

44. Seifert, A.; Schlomann, A.; Rietz, C.; Schelling, H.R. The use of mobile devices for physical activity tracking in older adults' everyday life. Digit. Heal. 2017, 3, 205520761774008. [CrossRef] [PubMed]

45. Ga, R.; May, A.M.; van Overmeeren, E.J.; Simons, M.; Monninkhof, E.M. The Effect of Physical Activity Interventions Comprising Wearables and Smartphone Applications on Physical Activity: A Systematic Review and Meta-analysis. Sport Med. Open 2018, 4, 42. [CrossRef]

46. Lindsay Smith, G.; Banting, L.; Eime, R.; O'Sullivan, G.; van Uffelen, J.G.Z. The association between social support and physical activity in older adults: A systematic review. Int. J. Behav. Nutr. Phys. Act. 2017, 14, 1-21. [CrossRef] [PubMed] 
47. Hämmig, O. Health risks associated with social isolation in general and in young, middle and old age. PLoS ONE 2019, 14, e0219663. [CrossRef]

48. Yu, B.; Steptoe, A.; Chen, L.J.; Chen, Y.H.; Lin, C.H.; Ku, P.W. Social Isolation, Loneliness, and All-Cause Mortality in Patients With Cardiovascular Disease: A 10-Year Follow-up Study. Psychosom. Med. 2020, 82, 208-214. [CrossRef]

49. Barton, J.; Pretty, J. What is the best dose of nature and green exercise for improving mental health-A multi-study analysis. Environ. Sci. Technol. 2010, 44, 3947-3955. [CrossRef]

50. Lima, C.K.T.; de Medeiros Carvalho, P.M.; Lima, I.D.A.S.; de Oliveira Nunes, J.V.A.; Saraiva, J.S.; de Souza, R.I.; da Silva, C.G.L.; Neto, M.L.R. The emotional impact of Coronavirus 2019-nCoV (new Coronavirus disease). Psychiatry Res. 2020, 287, 112915. [CrossRef]

51. López-Bueno, R.; Calatayud, J.; Casaña, J.; Casajús, J.A.; Smith, L.; Tully, M.A.; Andersen, L.L.; López-Sánchez, G.F. COVID-19 Confinement and Health Risk Behaviors in Spain. Front. Psychol. 2020, 11, 1-10. [CrossRef] [PubMed]

(C) 2020 by the authors. Licensee MDPI, Basel, Switzerland. This article is an open access article distributed under the terms and conditions of the Creative Commons Attribution (CC BY) license (http://creativecommons.org/licenses/by/4.0/). 